Lorena DE SOUSA MIRANDA ${ }^{1}$ Ana LÍDIA CAVALCANTE2 Rafael MOTA PINHEIRO² Dayani GALATO2 Emília VITÓRIA SILVA²

\title{
Reconciliation of medications upon the admission of patients to the cardiology sector of a university hospital
}

\begin{abstract}
Introduction: The reconciliation of medications is an important process that impacts on patient safety during the level of care transition, a moment with high discrepancy rates that can lead to adverse reactions. Objective: To analyze the results of medication reconciliation in order to identify discrepancies between the medical prescription and the medications previously used by the patient. Method: A descriptive, cross-sectional study was conducted between May and November 2017 (until the second fortnight of the month), with patients admitted to the cardiology department of the University Hospital of Brasilia. Data was collected through interviews with patients, relatives and/or caregivers, and through consultation of the medical records. The reconciliation of medications was performed daily, from Monday to Friday, within 48 hours of the patient's admission to the unit, through a medication reconciliation form prepared by the author. Results: 90 patients were included in the study and a total of 297 discrepancies were found, 267 (90\%) being intentional and 30 (10\%), unintentional. Among the unintentional discrepancies, the most frequent was omission of medication in use by the patient (56\%). Of the intentional discrepancies, the dosage modifications were more common in $45 \%$ of the cases. Conclusion: The reconciliation of medications was a crucial clinical service for the identification and resolution of unintentional discrepancies between previously used medications and hospital medical prescription.
\end{abstract}

Keywords: Medication Reconciliation, medication errors, patient safety, Medication Adherence.

\section{Conciliação de medicamentos na admissão de pacientes no setor de cardiologia de um hospital universitário}

\section{Resumo}

Introdução: a conciliação de medicamentos é um processo importante que impacta na segurança do paciente durante a transição de nível de atenção, momento com altas taxas de discrepâncias que podem levar a reações adversas. Objetivo: analisar os resultados da conciliação de medicamentos, de modo a identificar discrepâncias entre a prescrição médica e os medicamentos previamente utilizados pelo paciente. Método: estudo descritivo transversal, conduzido no período de maio a novembro de 2017, com pacientes admitidos no setor de cardiologia do Hospital Universitário de Brasília. A coleta de dados ocorreu por meio de entrevistas com os pacientes, familiares e/ou acompanhantes e consulta ao prontuário. A conciliação de medicamentos foi realizada diariamente, de segunda a sexta-feira, em até 48 horas a contar da admissão do paciente na unidade, por meio de um formulário elaborado por uma das autoras. Resultados: 90 pacientes incluídos no estudo resultou em 297 discrepâncias encontradas, sendo 267 (89,9\%) intencionais e 30 (10,1\%) não intencionais. Entre as discrepâncias não intencionais, a mais frequente foi omissão de medicamento em uso pelo paciente $(56 \%)$. Das discrepâncias intencionais, as modificações de posologia foram mais comuns em $45 \%$ dos casos. Conclusão: A conciliação de medicamentos foi um serviço clínico farmacêutico crucial para a identificação e resolução de discrepâncias não intencionais entre os medicamentos de uso prévio e a prescrição médica hospitalar.

Palavras-chaves: reconciliação de medicamentos, erros de medicação, segurança do paciente, adesão à medicação.

\section{University Hospital of Brasilia} 2 University of Brasilia

Submitted: $31 / 12 / 18$

Resubmitted: $11 / 12 / 19$

Accepted: $31 / 12 / 19$

Blind reviewers

DOI: 10.30968/rbfhss.2019.104.0353

ISSN online: $2316-7750$

Corresponding Author:

Lorena de Sousa Miranda lolosousa792@hotmail.com 


\section{Introduction}

According to the report of the Institute of Medicine for the Prevention of Medication Errors ${ }^{1}$, on average, the hospitalized patient is susceptible to at least one medication error per day. According to the literature, the transition between different levels of health care is responsible for $27 \%$ of the errors in hospital and outpatient prescriptions, due to incomplete and inaccurate information filling which directly affects patient safety ${ }^{2}$. In addition to this clinical aspect, these errors generated costs of US $\$ 42$ billion, in data compiled from $2017^{3}$. However, in Brazil, data on death statistics related to medication errors are not yet available ${ }^{4}$.

In order to avoid these discrepancies and potential medication errors, the reconciliation of medications can be used ${ }^{5}$. To materialize it, the health professional elaborates a complete, detailed and updated list of all drugs used by the patient, including the name of the drug, dose, pharmaceutical form, frequency of use and route of administration, before changing the level of care, comparing this information with the medical record or hospital medical prescription ${ }^{6.8}$.

Drug reconciliation is one of the clinical services that pharmacists can perform and which are legally supported in Brazil, through Resolution No. 585 of the Federal Pharmacy Council (Conselho Federal de Farmácia, CFF) of August $29^{\text {th }}, 2013$, which regulates the performance of the pharmaceutical professional in the area of clinical pharmacy

Some studies have shown good results in reconciling drugs in health services. A systematic review, with meta-analysis, shows a reduction in adverse reactions (67\%), emergency room care (28\%) and hospital readmission (19\%), as a result of pharmaceutical reconciliation ${ }^{10}$.

Reconciling medications also reduced the patient's risk of medication errors by $75 \%$ compared to those who did not receive this service ${ }^{11}$. These data indicate the importance of reconciliation to improve the safe and rational use of medications.

In this context, the main objective of this study was to describe and characterize the reconciliation of drugs in patients admitted to the cardiology sector of the University Hospital of Brasilia (Hospital Universitário de Brasília, HUB), in order to identify discrepancies between the medical prescription and the drugs previously used by the patient, aiming at preventing medication errors and at promoting the rational use of medications.

\section{Methods}

A descriptive and cross-sectional study was carried out, which involved patients admitted to the cardiology sector at the University Hospital of Brasília (HUB), located in Brasília - Federal District. The HUB is a tertiary-level teaching hospital that provides free care to the population.

The cardiology unit of the HUB has 19 hospital beds, ten belonging to the infirmary and nine to the Coronary Unit (COU). Daily visits are carried out at the bedside of the patients with the presence of the entire multidisciplinary team. The infirmary supports the care of patients who are affected by some type of cardiovascular disease, but who are clinically stable. It also includes patients who will undergo diagnostic tests and invasive procedures such as catheterization and angioplasty. The coronary care unit hospitalizes patients at high cardiovascular risk who require intensive care and 24-hour monitoring.

Data collection took place between the months of May and November 2017 (up to the second half of the month) and was carried out by a resident pharmacist through interviews with patients, family members or companions, and through consultation of the electronic medical records. The form used presented questions regarding demographic characteristics, such as gender, schooling, skin color and age, in addition to clinical and pharmacotherapeutic data of the patients.

The reconciliation of medications was performed daily, from Monday to Friday, within 48 hours of the patient's admission to the unit, using a form prepared by one of the researchers. The patients who were hospitalized on holidays or weekends were interviewed on the first following business day.

The study included patients over 18 years of age and who used at least one medication before admission, with a hospital stay of more than 48 hours. In the case of patients with cognitive, physical or motor disabilities, the companion signed the Free and Informed Consent Form (FICF). Patients who were transferred from the unit, were discharged or died less than 48 hours after admission and those who were hospitalized only for exams or procedures were excluded from the study.

After the reconciliation of medications by a resident pharmacist, the differences between the list of drugs that the patient used at home and the medical prescription for admission were identified and characterized as discrepancies. These differences may be related to the dose, frequency and route of administration, in addition to the inclusion or omission of a drug or even the occurrence of therapeutical duplicity?.

Discrepancies were classified as intentional ${ }^{12,13}$ and unintentional ${ }^{14}$ after approaching the medical team. The former can be characterized in the following manners: i. medical decision not to prescribe a drug based on the patient's clinical situation; ii. medical decision to change the patient's medication based on his or her clinical situation; iii. changes in drug dosage (route, dose and frequency of administration) based on the patient's clinical situation; iv. substitution of a medication for another one standardized in the hospital.

Regarding unintentional discrepancies, which can be considered as medication errors ${ }^{15}$, are observed when either of the following is present: i. omission of medication in use by the patient; ii. insertion of a medication not used by the patient; iii. incorrect route, frequency and time of administration; iv. incorrect dose; v. therapeutic duplicity; vi. duplicity of administration; vii. drug interaction.

The drugs involved in the intentional and unintentional discrepancies were categorized in the first level (main anatomical group), that is, represented by a letter corresponding to the organ or system in which the medication operates, according to the Anatomical Therapeutic Chemical (ATC) classification system. In addition, the mean number of drugs used per patient and the number of discrepancies were obtained, as well as cases of allergies to drugs. For the purposes of this study, the use of five or more medications was considered as polypharmacy ${ }^{22}$.

Tocorrectthe discrepanciesfound, the resident pharmacistmadeinterventions with the medical team, which were recorded in the patients' medical records.

The data obtained were collected in the Excel program and analyzed using descriptive statistics (measures of mean, standard deviation, median, mode, sum and percentage) using the SPSS version 23 statistical package for Windows.

This work is derived from two projects approved by the Ethics Committee of the Medical School of the University of Brasilia (CEP-FM-UnB): i. "Reconciliation of medications upon the admission of patients to the cardiology ward of a university hospital", 64747417.2.0000.5558; and i. "Reconciliation of drugs upon the admission of patients to the cardiology sector of a university hospital", CAAE: 68505717.6.0000.5558.

\section{Results}

During the study period, 156 patients were admitted to the cardiology sector. Of these, 64 did not meet the inclusion criteria, as they entered the unit by being transferred from the hospital of origin to perform catheterization or angioplasty, had a length of hospital stay of less than 48 hours and did not use medications for continuous treatment before admission. Of the patients who met the inclusion criteria, two refused to participate in the research. Thus, a total of 90 patients included in the study was obtained.

The demographic characteristics of the patients, of the use of the services, and of the reporting of allergies to food and medications are shown in Table 1. It is noteworthy that the mean age of the patients was 62 years old ( $S D=13.04)$, ranging from 1 to 90 years old and with a median of 64 .

596 medications in use by patients were observed. The data regarding the use of the Service and the discrepancies are shown in Table 2. In view that that the literature considers unintended discrepancies as medication error ${ }^{20}$, then a total of 30 medication errors were obtained.

It is observed that the majority of the unintentional discrepancies were due to the omission of a medication in use by the patient and that, after the pharmaceutical intervention, the medications were included in the prescription by the physician.

These were classified according to the main anatomical groups of the ATC system. Of the prescription drugs, 286 (47.9\%) were involved in discrepancies. It is noteworthy that the cardiovascular system medications (C) were the most frequent among the discrepancies. The distribution of the groups involved in the discrepancies is shown in Table 3.

\section{Discussion}

The findings of this study demonstrate that patients admitted to the hospital's cardiology sector undergo a consistent change in the pharmacological therapy, which leads to almost $50 \%$ of discrepancies when comparing the list used at home to that used in the hospital. However, most of the changes are intentional, based on the patient's own clinical condition or on the modification of the dosage. The unintended discrepancies are due in particular to the omission of medications. 
Table 1. Demographic characteristics of the patients admitted to the cardiology sector at the University Hospital of Brasília, 2018.

\begin{tabular}{lc}
\hline Variables & Results \\
\hline Demographical data n(\%) & \\
Gender & $45(50.0)$ \\
Male & $45(50.0)$ \\
Female & \\
Schooling & $14(15.6)$ \\
No studies & $9(8.9)$ \\
Complete Elementary School & $50(55.6)$ \\
Incomplete Elementary School & $8(8.9)$ \\
Complete High School & $3(3.3)$ \\
Incomplete High School & $4(4.4)$ \\
Complete Higher Education & $3(3.3)$ \\
Incomplete Higher Education & \\
Skin color & $32(35.6)$ \\
White & $18(20.0)$ \\
Black & $2(2.2)$ \\
Asian & $38(42.2)$ \\
Brown & \\
Hypersensitivity to medications and foods & $20(22.2)$ \\
Patients with reports of allergies to medications & \\
Medications related to allergies according to the patients & $6(6.7)$ \\
Dipyrone & $3(3.3)$ \\
Scopolamine & $3(3.3)$ \\
Metoclopramide & $7(7.8)$ \\
Patients with reports of allergies to foods & \\
Seads related to allergies according to the patients & \\
Milk & \\
Pork & \\
\hline Source: Own work. & $(1.1)$ \\
\hline
\end{tabular}

Table 2. Profile of service use by the patients in cardiological care and distribution of the identified discrepancies.

\begin{tabular}{lc}
\hline Data & Total N=90 \\
\hline Service use information & Mean \\
Mean length of hospitalization stay in days & $12(\mathrm{SD}=12.25)$ \\
Mean of medications used before admission & $7(\mathrm{SD}=3.33)$ \\
Medication use & $\mathrm{n}(\%)$ \\
Patients in polypharmacy & $64(70.3 \%)$ \\
Patients with more than ten medications prescribed & $57(63.7 \%)$ \\
Discrepancies in the prescription & Mean \\
Discrepancies per patient & $3(1.89)$ \\
Medications involved in discrepancies & $\mathbf{n}(\%)$ \\
Yes & $297(49.8)$ \\
No & $299(50.2)$ \\
Type of discrepancies & $\mathbf{n}(\%)$ \\
Intentional discrepancies & $267(89.9)$ \\
Unintentional discrepancies & $30(10.1)$ \\
Situations of unintentional discrepancies & $\mathbf{n}(\%)$ \\
Omission of medications & $17(56.0)$ \\
Wrong dose & $6(20.0)$ \\
Wrong frequency of administration & $2(7.0)$ \\
Wrong administration time & $2(7.0)$ \\
Inadequate inclusion of medications not used by & $2(7.0)$ \\
the patient & $1(3.0)$ \\
Duplicity of administration & $\mathbf{n}(\%)$ \\
Situations of intentional discrepancies & $21(45.3)$ \\
Dosage changes & $115(43.0)$ \\
Medical decision to not prescribe a medication & $28(11.0)$ \\
based on the clinical situation of the patient & $3(1.0)$ \\
Change of medication & $\mathbf{n}(\%)$ \\
Substitution for standardized medications in the hospital & $30(77.5)$ \\
Response to the interventions performed & $10(22.5)$ \\
Accepted & \\
Not accepted & \\
\hline & Stand \\
\hline
\end{tabular}

Source: Own work.

Table 3. Distribution of the medications involved in the discrepancies categorized in the first level (main anatomical group according to the ATC system).

\begin{tabular}{|c|c|c|c|c|}
\hline & $\begin{array}{l}\text { Medications according to the main anatomical group } \\
\text { of the ATC }\end{array}$ & $\begin{array}{l}\text { Intentional discrepancy } \\
\mathrm{n}(\%)\end{array}$ & $\begin{array}{l}\text { Unintentional discrepancy } \\
\mathbf{n}(\%)\end{array}$ & $\begin{array}{l}\text { Total } \\
\mathbf{n}(\%)\end{array}$ \\
\hline $\mathrm{C}$ & Cardiovascular system & $171(96.1)$ & $7(3.9)$ & $178(60.0)$ \\
\hline A & Feeding tract and metabolism & $57(89.1)$ & $7(10.9)$ & $64(21.5)$ \\
\hline B & Blood and blood-forming organs & $18(85.7)$ & $3(14.3)$ & $21(7.1)$ \\
\hline $\mathrm{N}$ & Nervous system & $10(90.9)$ & $1(9.1)$ & $11(3.7)$ \\
\hline $\mathrm{R}$ & Respiratory system & $5(62.5)$ & $3(37.5)$ & $8(2.7)$ \\
\hline M & Muscle-skeletal system & $2(50.0)$ & $2(50.0)$ & $4(1.3)$ \\
\hline G & Genitourinary system and sex hormones & $1(33.3)$ & $2(66.7)$ & $3(1.0)$ \\
\hline $\mathrm{J}$ & Anti-infectives for systemic use & $0(0.0)$ & $3(100.0)$ & $3(1.0)$ \\
\hline S & Sensory organs & $2(66.7)$ & $1(33.3)$ & $3(1.0)$ \\
\hline $\mathrm{C}$ & Systemic hormonal preparations, excluding sex hormones and insulins & $0(0.0)$ & $1(100.0)$ & $1(0.3)$ \\
\hline $\mathrm{L}$ & Antineoplastics and immunomodulating agents & $1(100.0)$ & $0(0.0)$ & $1(0.3)$ \\
\hline
\end{tabular}

\footnotetext{
Source: The author:
} 
The profile of the cardiology patients included in this study was of elderly individuals, with low schooling and with a majority of brown skin color. The first two characteristics can contribute to the worsening of the patient's condition, added to the comorbidities, since they may not correctly understand the information they receive from the medical team ${ }^{17}$.

It was also observed that there was no predominance of males over females, diverging from data found in the literature, where there is a greater number of men ${ }^{14,18}$ and/or women ${ }^{12,19,16,20-21}$.

Regarding the use of medications used before admission, the mean found in this research was very close to that found in the study by Fernandes et al. ${ }^{12}$ (mean of 6.2), also performed in a cardiology unit, which may be related to the treatment adopted for the heart problem itself and to the comorbidities common to this population.

Although the use of multiple medications, or polypharmacy, is beneficial to the patient, if prescribed according to the best available evidence ${ }^{23}$, it can make him more susceptible to present adverse effects related to the use of these drugs ${ }^{23}$.

The percentage of patientswhoreported havingalreadybeenhypersensitive to drugs should be further investigated. According to Mobs and Pfutzner, $25 \%$ of all the adverse reactions can be considered hypersensitivity reactions and categorized as allergies or pseudoallergies ${ }^{24}$. Therefore, there may have been confusion between the signs and symptoms of a possible adverse reaction with allergies, or having difficulties in adapting to the treatment and developing resistance to its use. In this context, an accurate diagnosis of the adverse event is recommended, assessing the patient's medical history, clinical symptoms and pathogenesis ${ }^{24}$.

Among the intentional discrepancies, the most prevalent type in our study, as previously described, was the medical decision to modify the dosage of the medication (route, dose and/or frequency of administration) based on the patient's clinical situation, which is similar to the findings of another study, in which $42 \%$ of the discrepancies were for this reason ${ }^{26}$. In contrast, in the work by Oliveira et al. ${ }^{13}$, the medical decision not to prescribe medication based on the patient's clinical situation was the most frequent, with $80.64 \%$. This behavior of the medical team in the cardiology sector at the HUB can be interpreted as an adjustment to the patient's drug treatment, according to his clinical status.

In two studies also carried out in cardiology units of university hospitals, the number of discrepancies in the first was 117 , of which $50.4 \%$ were unintentional ${ }^{16}$ and, in the second, the total found was 181 discrepancies, with $17.7 \%$ being unintentional ${ }^{12}$. In our study, a smaller percentage of unintentional discrepancies was observed, around $10 \%$, but they are still worrisome data, considering that a large part refers to the omission of medications after hospitalization.

Among the unintended discrepancies, the most frequent error found was the omission of medications, which can cause treatment interruption and, as a consequence, damage to the patient ${ }^{13}$. An important case that occurred in this study was a patient living with AIDS who had his anti-retroviral regimen omitted at the time of admission and that, shortly after the pharmaceutical intervention, the drugs were inserted into the hospital prescription. The predominance of omission may be linked to obtaining an incomplete and poorly accurate medication history, as a result of a poorly conducted anamnesis. In contrast, in other studies the most common errors were the following: incomplete prescription ${ }^{16}$, different dose, route or time ${ }^{12,18}$ and addition ${ }^{11}$. Complementing this information, Kawan et al. ${ }^{26}$ reported that the inadvertent discontinuation of hypocholesterolemic agents, thyroid hormone replacement therapy, therapy for osteoporosis and gastritis may carry a greater risk for adverse events and readmission in the next 30 days. However, these same authors warn that reconciliation is more effective when accompanied by another clinical service, such as discharge guidance ${ }^{27}$.

In the context of the cardiology sector of the University Hospital of Brasília, 10\% of the discrepancies could be characterized as potential medication errors, since there was no intention to commit them; however, they were resolved by the pharmacist's intervention.

The pharmaceutical interventions performed in this work through the drug reconciliation process showed good acceptance by the physicians; this led to a decrease in the number of medication errors, which occur when the patient moves between the different levels.

The therapeutic group with the greatest number of discrepancies was the cardiovascular system, which is perfectly compatible with the fact that the study was carried out exclusively in the cardiology unit of the hospital, and in agreement with another study involving this type of patient ${ }^{16}$.

However, it is noteworthy that the classification and definition of the discrepancies as intentional and unintentional varies according to the study that describes them. This variability, which makes it difficult to compare data ${ }^{16}$, may be due to the different parameters chosen by each study to distinguish between intentional and unintentional discrepancies. The standardization of these concepts, and contextualization for the Brazilian scenario, could be an excellent initiative to be carried out by research groups and professional entities involved in clinical pharmacy and patient safety and in promoting the rational use of medications.

In this study, some limitations should be considered, such as the fact that the hospital does not have a clinical pharmacist in the cardiology unit, this activity being performed by the resident pharmacist; in this case, it is not feasible for this professional to remain full time in the hospitalization unit. Another barrier found was the lack of communication with the medical team, which made it difficult to identify and classify the discrepancies as intentional and unintentional and to conduct pharmaceutical interventions.

In addition, it is noteworthy that this study did not evaluate the possible impact of the discrepancies in causing damage to the patients as performed in other studies, where they were categorized into classes (1,2 and 3), according to the severity of the potential damage. Just as it was not possible to provide guidance at hospital discharge. However, the investigated sample is higher than that of other studies with cardiac patients $\mathrm{s}^{12,16}$ or of other clinics ${ }^{14}$.

This work had positive impacts, such as the potential reduction of unintentional discrepancies and, consequently, a decrease in medication errors, the possibility of greater interaction with the multidisciplinary team, and promotion of patient safety.

The future challenges are the implementation of the clinical drug reconciliation service in all clinics of the hospital, with the presence of clinical pharmacists in each sector together with the entire multidisciplinary team, in addition to the continuity of service in the cardiology unit. It is also estimated that the service and its impacts on the hospital and patients will be evaluated.

\section{Conclusions}

The results of this study demonstrated that the drug reconciliation process is extremely important for the identification and resolution of discrepancies between previously used drugs and the hospital medical prescription. Most of the discrepancies identified in our study were intentional, the most frequent being the medical decision to change the dosage based on the patient's clinical situation. Among the unintentional ones, the most common error was the omission of a medication in use by the patient, corroborating data found in the literature. This causes interruption in the treatment of chronic diseases, which can cause harm to patients.

The performance of the resident pharmacist in this process has reduced the number of medication errors through interventions carried out with the medical team that showed good acceptance, as well as it enabled greater interaction with the multi-professional team, contributed to the promotion of the rational use of medications and to the optimization of the pharmacotherapy, promoting patient safety and adherence to the proposed treatment. This work reinforces the importance of implementing this routine in the institution but, for this to be possible, it is necessary to include the clinical pharmacist in the multidisciplinary cardiology team.

\section{Funding sources}

Lorena de Sousa Miranda received a grant from the Ministry of Education as a multi-professional resident in cardiopulmonary care pharmacy from 2016 to 2018.

\section{Contributors}

LSM: conception, design, analysis and interpretation of data, preparation of the article and responsibility for all work informations, ensuring accuracy and integrity of any part of the work. ALSC: review of the collected data and review of the manuscript. DG: critical review of the manuscript, mainly in the methods. RMP: conception and critical review of the manuscript. EVS: conception, analysis, interpretation of data, guidance in the preparation, critical review of the manuscript and final approval of the version to be published.

\section{Conflicts of interest}

The authors declare no conflicts of interest in relation to this article. 


\section{References}

1. Institute of Medicine. Preventing medication errors. Washington, DC: National Academies Press; 2006.

2. Lombardi NF, Mendes AE, Lucchetta RC, et al. CJ. Analysis of the discrepancies identified during medication reconciliation on patient admission in cardiology units: a descriptive study. Rev. Lat. Am. Nursing. 2016 Aug 15; 24 (8): 2753-2760.

3. Sheikh A, Dhingra-Kumar N, Kelley E et al. The third global patient safety challenge: tackling medication-related harm. Bull World Health Organ. 2017; 95: p.546-547. Artigo submetido em 2018.

4. Ministério da saúde (BR), Anvisa, Fiocruz, FHEMIG. Protocolo de segurança na prescrição, uso e administração de medicamentos.[Internet]. 2013 Available from: https://www20.anvisa.gov.br/segurancadopaciente/index $\mathrm{php} / \mathrm{publicacoes} /$ item/seguranca-na-prescricao-uso-e-administracao-de-medicamentos. Accessed on 2018 Aug 08.

5. Kitts NK, Reeve AR, Tsul L. Care transitions in elderly heart failure patients: current practices and the pharmacist's role. Consult Pharm 2014; 29(3): 179 190.

6. Conselho Federal de Farmácia. Serviços farmacêuticos diretamente destinados ao paciente, à família e à comunidade: contextualização e arcabouço conceitual [Internet]- Brasília: Conselho Federal de Farmácia, 2016. Disponível em: http://www.cff.org.br/userfiles/Profar_Arcabouco_TELA_FINAL. pdf. Accessed on 2018 Aug 08.

7. Conselho Federal de Farmácia. Resolução no 585 de 29 de agosto de 2013 [Internet]. Brasília: Conselho Federal de Farmácia, 2013;1-11. Disponíve em: http://www.cff.org.br/userfiles/file/resolucoes/585.pdf. Accessed on 2018 Aug 10

8. Chhabra PT, Rattinger GB, Dutcher SK et al. Medication reconciliation during the transition to and from long-term care settings: A systematic review. Res Soc Adm Pharm [Internet]. 2012;8(1):60-75. Disponível em: http:// dx.doi.org/10.1016/j.sapharm.2010.12.002. Accessed on 2018 Aug 08.

9. Sinvani LD, Beizer J, Akerman M, et al. Medication Reconciliation in Continuum of Care Transitions: A Moving Target. J Am Med Dir Assoc. 2013;14(9):668-672.

10. Mekonnen AB, McLachlan,AJ, Brien JE. Effectiveness of pharmacist-led medication reconciliation programmes on clinical outcomes at hospital transitions: a systematic review and meta-analysis. BMJ Open 2016; 6: e010003.

11. Chiewchantanakita D, Meakchaia A, Pituchaturonta N, et al. The effectiveness of medication reconciliation to prevent medication error: A systematic review and meta-analysis. Res Social Adm Pharm.

12. Magalhães GF, Santos GN, Rosa MB, et al. . Medication reconciliation in patients hospitalized in a cardiology unit. PLoS One. 2014;9(12):1-12.

13. Oliveira JS, Vielmo L, Beck ST, et al. reconciliação farmacoterapêutica na otimização da terapia. Experiências Exitosas de Farmacêuticos no SUS. Conselho Federal de Farmácia 2016;4(4):126-132

14. Frizon F, Santos AH, Caldeira LF, et al. Reconciliação de medicamentos em hospital universitário. Rev enferm UERJ.2014; 22(4):454-60.

15. Knez L, Suskovic S, Rezonja R, et al. The need for medication reconciliation: A cross-sectional observational study in adult patients. Respir Med [Internet] 2011; 105(1):S60-S66..

16. Lombardi NF, Mendes AEM, Lucchetta RC, et al. Analysis of the discrepancies identified during medication reconciliation on patient admission in cardiology units: a descriptive study. Rev. Latino-Am. Nursing. 2016;24:1-7.
17. Shah F, Burack O, Boockvar KS. Perceived barriers to communication between hospital and nursing home at time of patient transfer. JAMDA 2010;11(4):239-245

18. San José Ruiz B, Serrano De Lucas L, López-Giménez LR, et al. Medication reconciliation at hospital admission: Results and identification of target patients. Rev Calid Asist. 2016; 31(1):36-44.

19. Abdulghani KH, Aseeri MA, Mahmoud A, et al. The impact of pharmacist-led medication reconciliation during admission at tertiary care hospital. Int J Clin Pharm. 2017;1-7.

20. Saavedra-Quirós V, Montero-Hernández E, Menchén-Viso B et al. Medication reconciliation at admission and discharge. A consolidated experience. Rev Calid Asist. 2016; 31(1):45-54

21. Rubio-Cebrián B, Santaolalla-García I, Martín-Casasempere I, Segura-Bedmar M. [Medication reconciliation in patients over 75 years]. Rev Calid Asist. 2016;31 (1):29-35

22. Nascimento RCRM, Álvares J, Gerra Junior AA et al. Polifarmácia: uma realidade na atenção primária do Sistema Único de Saúde. Rev Saude Publica. 2017; 51(2):19s.

23. Gandhi TK, Weingart SN, Borus J, et al. Adverse drug events in ambulatory care. N Engl J Med 2003;348:1556.

24. Möbs C, Pfützner W. Diagnostik von Arzneimittelüberempfindlichkeiten [Diagnostics of drug hypersensitivity reactions]. Hautarzt. 2017;68(1):1928

25. Lindenmeyer LP, Goulart VP, Hegele V. Reconciliação medicamentosa como estratégia para segurança do paciente oncológico - resultado de um estudo piloto. Rev Bras Farm Hosp Serv Saúde São Paulo [Internet]. 2013; n.4:51-5. Available from: http://www.sbrafh.org.br/rbfhss/public/artigos/2013040408000469BR.pdf. Accessed on 2018 Sep 10.

26. World Health Organization. Medication without harm. WHO Global Patient Safety Challenge. Geneva: World Health Organization. Guideline.

27. Kwan, JL, Lo L, Sampson M, KG. Medication reconciliation during transitions of care as a patient safety strategy: a systematic review. Ann Intern Med. 2013; 158(5):397-403. 